\title{
Kota Bharu Islamic City - The Concept of a New Cultural Tourism Product
}

\author{
M.R. Mohd Nasir ${ }^{1}$, I.H. Salleh ${ }^{2}$ \\ ${ }^{1,2}$ Department of Art and Design, Faculty of Art, Computing and Creative Industry, Sultan Idris \\ Education University, 35900 Tanjung Malim, Perak Darul Ridzuan, Malaysia
}

\begin{abstract}
This study introduces the concept of the Kota Bharu Islamic city in the eyes of tourists, with focus on recent trends affecting Malay cultural landscape and urban planning issues in Kelantan. The aims of this study are to introduce the concept of the Kota Bharu Islamic City as the new cultural tourism product in Malaysia as well as to enhance the reputation of the concept at the highest peak and Malay community development in Malaysia by using multiple methods including literature review, site observation and document analysis. The Kelantan Malay heritage should be highlighted as a main consideration in the future planning to avoid further damage or loss of valuable heritage. Finally, a regional vernacular tradition should be set as the focal point in making of the Islamic City of Kota Bharu without mimicking from other Islamic countries and subsequently the concept of the Kota Bharu Islamic City to be promoted as a new cultural tourism product in Malaysia will be successful.
\end{abstract}

\section{Introduction}

Kota Bharu is the state capital and has become the central point for Kelantan's administrative and dealing activities. As a border state and the former vassal state of Thailand, Kelantan has absorbed many influences from Thai customs and traditions that help to make the state's culture distinct from those of other states of Malaysia. The investigation highlights the traditional cultural elements that can be offered to contemporary planners, landscape architects, and municipal administrators in their endeavors to conserve the integrity and the beauty of the Kelantan Malay cultural landscape as well as the approaches that have been used by Kota Bharu Municipal Council in creating the new landscape, especially in the city centre as a tourist attraction.

\subsection{Tourism Promotion Approach}

The approach in promoting a new tourism product should be strengthened globally with full contribution of governments, private agencies and the media. In order to encourage reiterate visits by tourists to the area of new tourism products, it requires a variety of promotional methods, namely by introducing or re-branding the concept of traditional Malay cultural landscape to the public and increase the planning and development of the city which has preserved the authenticity of the place based on their local culture [1]. 


\subsection{Tourism as Experience and Reminiscence}

Progressively there is recognition that the tourism industry is in the experience and memory business. This recognition requires destinations to provide for a variety of experiences from passive to active, including models that allow the visitor to design and mold their experience towards a unique set of activities [2].

Re-branding the tourism product will make it more valuable and offer immeasurable experience for tourists [3]. Products that considered in this branding should have unique characteristics which can show the identity of localities and combine it with specific themes like the concept and approaches that have been used by Kota Bharu Municipal Council in creating the new landscape incorporated with Islamic values and the traditional identity of the Kelantan Malay into its design principles.

\section{The Nature of Cultural Landscape}

Cultural landscape refers to the vernacular landscape that has evolved through use by the people whose activities or occupancy shaped that landscape. Through the social or cultural practices of an individual, family or a community, the landscape reflects the physical, biological, and cultural character of those everyday lives.

Cultural landscapes are the combined products of the interaction of people and nature. These have been categorized as 'defined', 'evolved' and 'associative' [4]. Further, the issues and challenges facing landscape architects working on cultural landscapes deemed to be multiple and complex, include addressing documentation, selecting an appropriate preservation approach and philosophy, and incorporating multiple values both tangible and intangible. One of the earliest definitions of the cultural landscape who argued [4-5]:

"The cultural landscape is fashioned from a natural landscape by a cultural group. Culture is the agent, the natural area is the medium, and the cultural landscape is the result. Under the influence of a given culture, itself changing through time, the landscape undergoes development, passing through phases and probably reaching ultimately the end of its cycle of development. With the introduction of a different, alien culture, a rejuvenation of the cultural landscape sets in, or a new landscape is superimposed on remnants of the old one"

Commencing from this statement, researchers have concluded that the cultural landscape proficient as a fundamental impression of the social culture and economy of a society who inhabit every corner of this world. It is proposed that, although new development should still proceed apace, it should respect the sense of place, its history, built heritage and traditional characteristics.

\subsection{Cultural Heritage as a Resource for Tourism}

Cultural tourism refers to tourism activities that create the elements of culture as the main magnetism includes the daily routine, the way to entertain guests, food and beverage, architecture and style, handicrafts as well as all the elements that personify the way of life in a specific place [6]. Consequently, cultural tourism has been defined as the movement of persons to cultural attractions away from their normal place of residence, with the intent to get together and experiences the diversity of cultures worldwide. In order to smooth the progress of sustainable use, it is important for contemporary planners, landscape architects, municipal administrators and tourists itself to understand the characteristics of this resource, particularly:

(1) The intersection of physical and community or social attributes of heritage sites as important aspects of conservation and visitor experience the value of heritage as a cultural capital and how we measure it.

(2) The complexity in cultural heritage, beyond ideas of authenticity, those lead to contradictions and contested heritage.

(3) The potential of heritage properties to develop into tourist attractions whether or not they are identified as such. 


\subsection{The Concept of Islamic City}

Muslims seek their spiritual energy from the Quran and the example of Prophet Muhammad, the Sunnah and their social ideals from the history of early Islam. Islamic villages, towns and cities rarely conform to the geometric symmetry of urban planning who conceive their settlements as images of an ordered cosmos [7]. Thus, traditional settlements tend to respect norms in Islamic religious principles as well as reflect a social system that requires a balance between segregation in daily life, economic and religious life of a community.

However, they face their contemporary problems of government, economics, and education as well as their environment and suggested that the ideas of Islamic environmental design are based on three main formative values [8]:

(1) Environmental sensibility which is based on the natural topography, climate, garden and tools.

(2) Morphological integrity, based on size and scale.

(3) Symbolic clarity, based on tradition, culture and identity.

\section{The Concept of Kota Bharu Islamic City}

Kota Bharu, Kelantan was declared by the state government as an Islamic City since October 1st, 2005 , thus the city is now practicing Islamic principles in every aspect of daily life. Essentially, the urban design of the city is based on the state government slogan, Developing with Islam in the direction of creating a city which could be related to an Islamic identity. The basis of the Kota Bharu Islamic city was to build an environment that consists of three major connections, namely; human with God, human with human, and human with nature [9].

At the same time, the trade and industry spaces in the city will be upgraded to offer greater diversity along with exhorted people respect the nature and having a better understanding of divinity. Therefore, they have provided more religious spaces and buildings for the community, especially for the Muslim community.

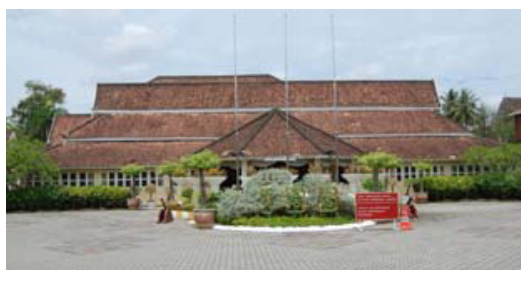

(a) The Palace of the Great Hall

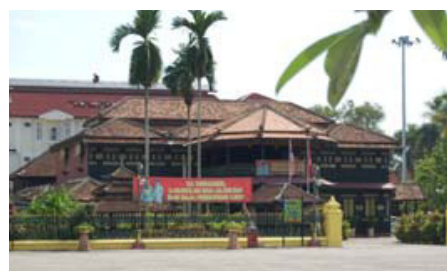

(b) Jahar Palace

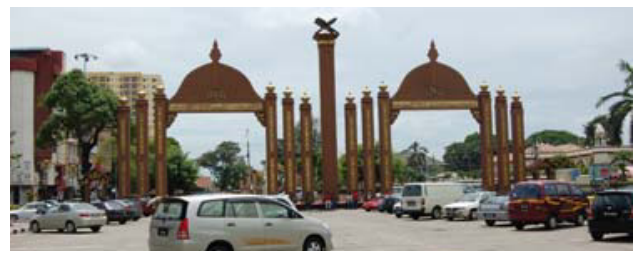

(c) The Sultan Ismail Arch area adapted from the entrance of the Palace of the Great Hall

Figure 1. $(\mathrm{a}-\mathrm{c})$ Among the historical building and artificial structure as a main tourist attraction that can be found in Kota Bharu, Kelantan (Source: Author, 2014)

Kota Bharu, as an Islamic City, represents a symbolic icon in the urban development of the Islamic state of Kelantan, Malaysia. One of the most visible Islamic iconographies is the prevalence of Jawi script which is a modified form of Arabic script used for writing the Malay language in the names of streets, shops, signboards and billboards. 

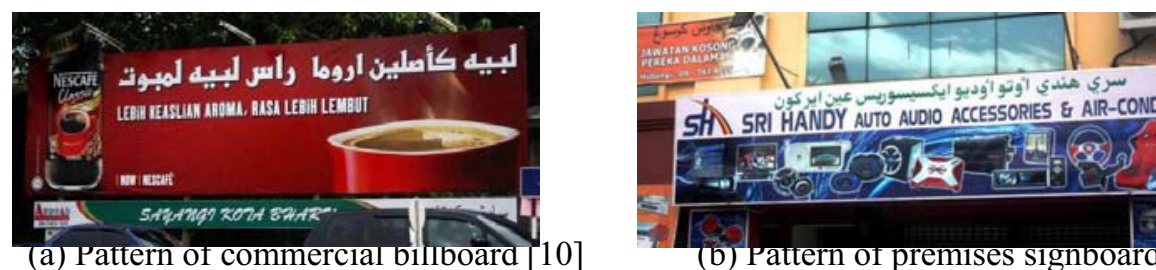

(D) Patern or premises signboard [11]

Figure 2. $(\mathrm{a}-\mathrm{b})$ Among the most visible Islamic iconographies in Kota Bharu, Kelantan is the use of Jawi writing in the names of streets, shops, signs and billboards.

Additionally, new buildings in the city centre must be decorated with the Arabesque pattern especially on the walls and facades.

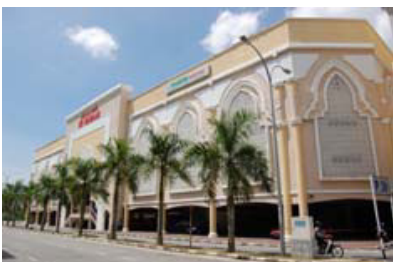

(a)

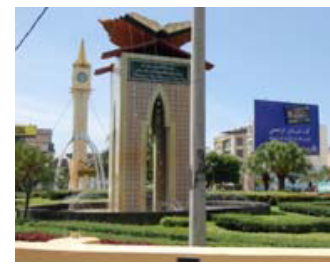

(b)

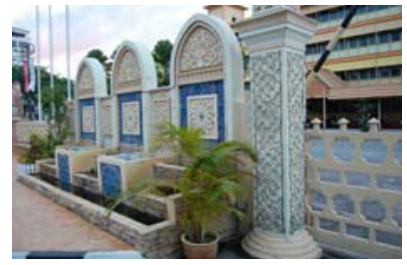

(c)

Figure 3. $(\mathrm{a}-\mathrm{c})$ Some of the Arabesque geometric patterns that can be seen in the new building and hard landscape elements in Kota Bharu, Kelantan (Source: Author, 2014)

\subsection{The basic concept of Kota Bharu Islamic city}

The Municipal Council of Kota Bharu has defined the Islamic city as a city where spaces promote an interrelationship among humans, environment and God. The objective of the Kota Bharu Master Plan can be described as the diagram below:

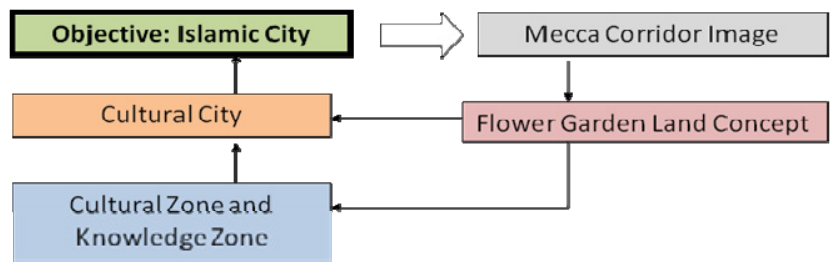

Figure 4. Objectives of the Kota Bharu Islamic City Master Plan [12]

In order to make sure that the objectives of the Islamic city can be realized, the Municipal Council of Kota Bharu has incorporated Islamic values and the traditional identity of the Kelantan Malay into its design principles on the Kota Bharu Municipal Council- Islamic City 2006-2015 Master Plan Report (MPKB-BI, 2006a), the criteria that have to be considered in landscape planning are as follows:

(1) Spiritual development of the community between humanity and God.

(2)Clean Environment as one of the Islamic requirements. The community has to treat the environment as God-created, to be cared for.

(3) A social relationship among the community.

Accordingly, design principles to indicate the Islamic city have been proposed, such as:

(1) Every design has to remind people about the almighty God.

(2) Every design has a good quality of space.

(3) Every design has to work well at the human scale in order to produce feelings of comfort and safety.

(4) Garden design should consider the human senses of feeling, smell and sight.

(5) Garden space should consider the flow and circulation for people's privacy. 


\section{Findings}

The study had advanced constructive ideas for improved practices in respect of the Kelantan Malay cultural landscape. It has also recommended principles and guidelines that might be developed in order to promote practices which are more respectful towards the Kelantan Malay cultural landscape and the concept of Islamic City itself.

From the documents analysis and site observation, it was clear that landscape planning strategy and practice in the Kota Bharu Islamic City is well developed in order to confer Islamic images upon civic and state identities. However, too many adaptations from other design concepts may change the authenticity of the traditional and vernacular design that has made Kelantan famous. New approaches should tackle the balance between traditional and Islamic design, so that the essence of the Kelantan vernacular landscape is not overridden and particularly helpful in making preliminary inferences about the kinds of factors that might exemplify traditional, neo-traditional and modern Islamic influences. These elements and indicators are summarised in Table 1.

Table 1. Design Elements Drawn from the Document Analysis Stage

\begin{tabular}{|c|c|c|c|}
\hline Design elements & Traditional & Neo-traditional & Modern Islamic \\
\hline Decorative arts & $\begin{array}{l}\text { Use of Kelantan Malay arts, crafts } \\
\text { and traditional games e.g. batik, } \\
\text { songket, silver craft, shadow play, } \\
\text { kite, giant drum and spinning }\end{array}$ & $\begin{array}{l}\text { Mixture of traditional } \\
\text { and modern Islamic }\end{array}$ & $\begin{array}{l}\text { Islamic arts and } \\
\text { identities from other } \\
\text { Islamic countries }\end{array}$ \\
\hline Ornament & Traditional floral pattern motifs & $\begin{array}{l}\text { Mixture of traditional } \\
\text { and modern }\end{array}$ & $\begin{array}{l}\text { Islamic decorative } \\
\text { motifs }\end{array}$ \\
\hline Building styles & $\begin{array}{l}\text { Use of Kelantan Malay vernacular } \\
\text { architecture, e.g. roof design }\end{array}$ & $\begin{array}{l}\text { Mixture of traditional } \\
\text { and modern }\end{array}$ & $\begin{array}{l}\text { Islamic decoration for } \\
\text { the wall and building } \\
\text { structure }\end{array}$ \\
\hline $\begin{array}{l}\text { Construction } \\
\text { materials }\end{array}$ & The use of timber materials & $\begin{array}{l}\text { Mixture of timber } \\
\text { and concrete }\end{array}$ & Concrete \\
\hline Water element & Traditional ceramic, terracotta pot & Mixture & $\begin{array}{l}\text { Geometric fountain as } \\
\text { reflection of paradise } \\
\text { garden }\end{array}$ \\
\hline Floor Design & Made from timber & Mixture & $\begin{array}{c}\text { Arabesque floor pattern } \\
\text { design }\end{array}$ \\
\hline $\begin{array}{l}\text { Calligraphy } \\
\text { design }\end{array}$ & Floral motifs & Mixture & $\begin{array}{c}\text { Use of Arabic } \\
\text { calligraphy and } \\
\text { Arabesque design motifs }\end{array}$ \\
\hline $\begin{array}{l}\text { Planting } \\
\text { strategies }\end{array}$ & $\begin{array}{l}\text { Tropical plants based on the Flower } \\
\text { Garden Land concept }\end{array}$ & Mixture & $\begin{array}{c}\text { Palm trees as dominant } \\
\text { and creation of Paradise } \\
\text { Garden }\end{array}$ \\
\hline $\begin{array}{l}\text { Example of the } \\
\text { palace }\end{array}$ & $\begin{array}{c}\text {-Palace of the Great Hall } \\
\text {-Kelantan Cultural Heritage } \\
\text { Museum (also known as Jahar } \\
\text { Palace) }\end{array}$ & Sultan Ismail Arch & $\begin{array}{l}\text {-State Mosque, which is } \\
\text { influenced by the } \\
\text { Islamic Moorish style } \\
\text { - Clock Tower } \\
\text { roundabout }\end{array}$ \\
\hline
\end{tabular}

\subsection{Drivers of Change in Cultural Landscapes}

It is clear that the cultural landscape is inherently dynamic rather than static, and is subject to continuous drivers of change (Figure 5). The presence of change drivers need not be incompatible with place authenticity provided designers have a sound understanding of the physical distinctiveness, activities and meanings of the locality in question. Drivers can be influenced through a combination of policy, planning, design and management. 


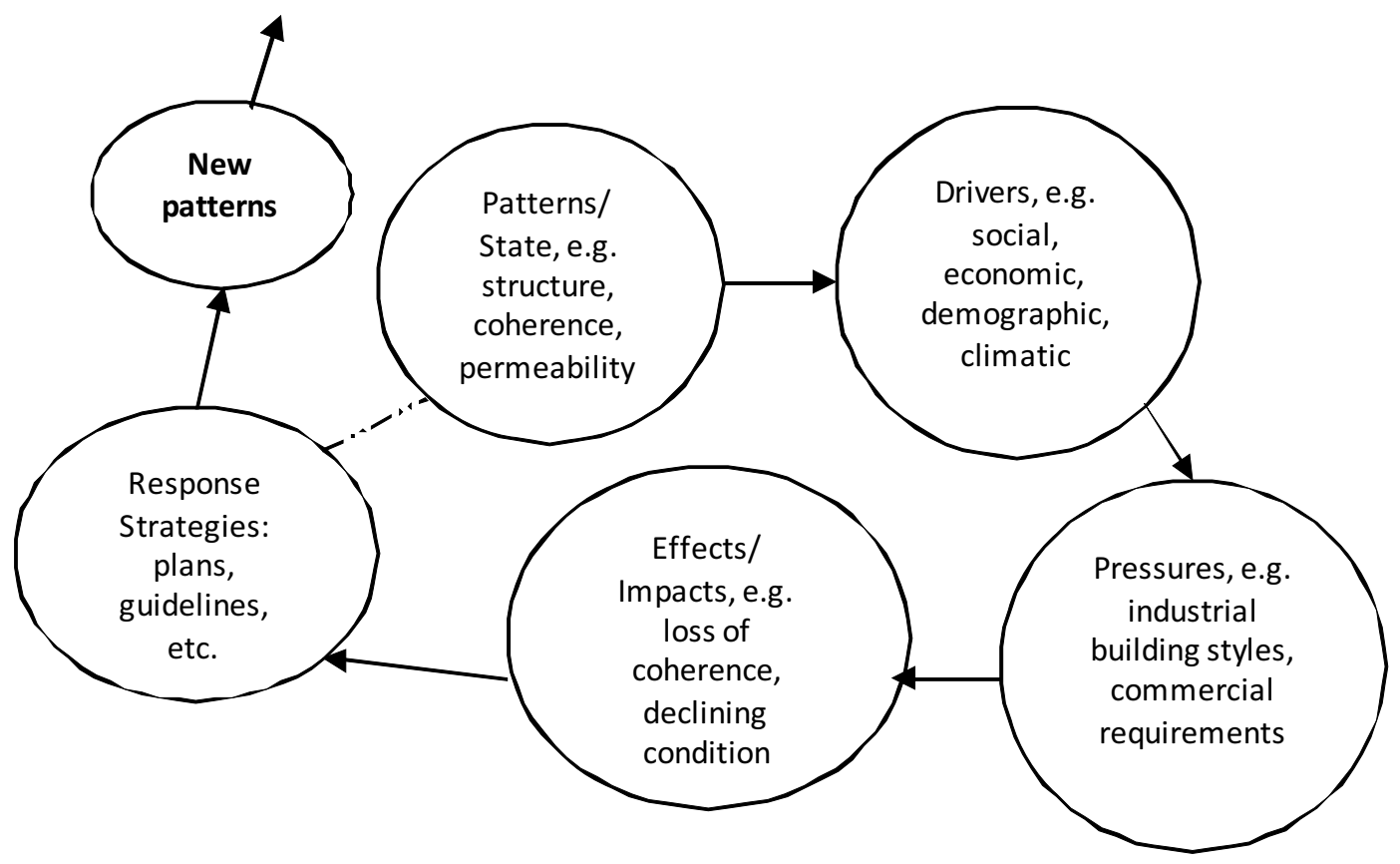

Figure 5. Drivers of Change in Cultural Landscapes [13]

Referring to the current situation in Kelantan, the drivers of landscape change can be summarised as below:

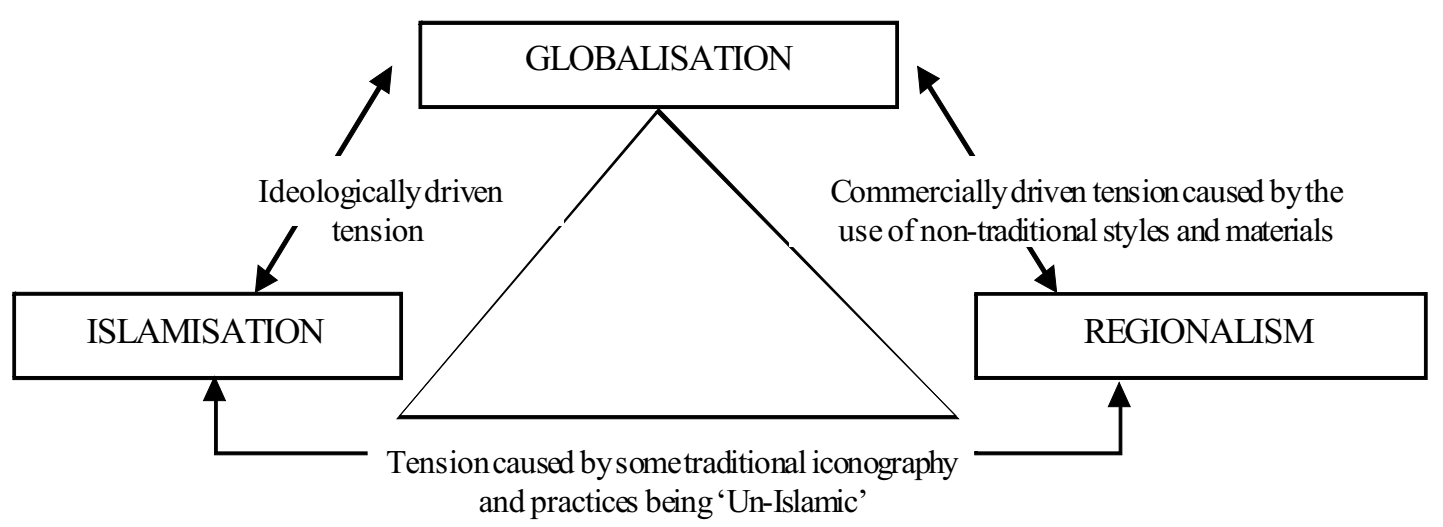

Figure 6. Drivers of Cultural Landscape Change in Kelantan

\subsection{The Acts and Guidelines}

Kota Bharu, Kelantan is also deemed to be a Cultural City has many traditional arts and cultural practices that remain, it is necessary for the local government to promote the richness of the culture as part of the Kelantan Malay landscape. Thus, it is part of the official planning strategy of the Kota Bharu Municipal Council to preserve and retain the Kelantan Malay culture, in a manner that is compatible with the measures for Developing with Islam. 
In order to realize the local identity and regional style, Kelantan vernacular architecture and craftsmanship have been applied widely in relation to the hard landscapes element and street landscape elements. These can be seen through the pillar, floor, wall and decoration of buildings.

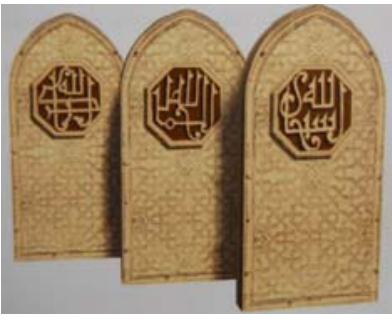

(a) Decorative panel

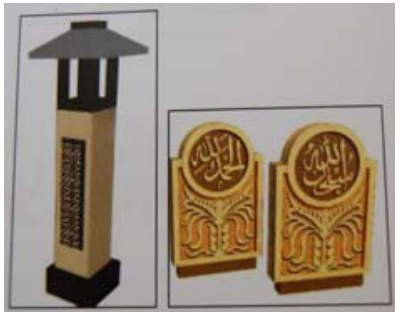

(b) Bollard

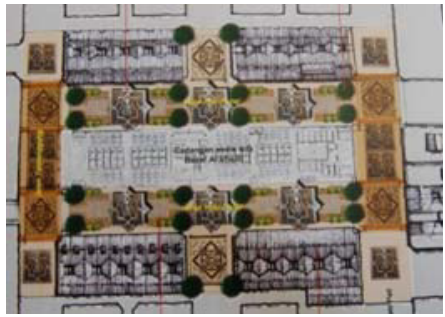

(c) Floor pattern

Figure 7. (a-c) Pattern of the Street Landscape and Hard Landscape Design that has Been Used in Kota Bharu, Kelantan [12]

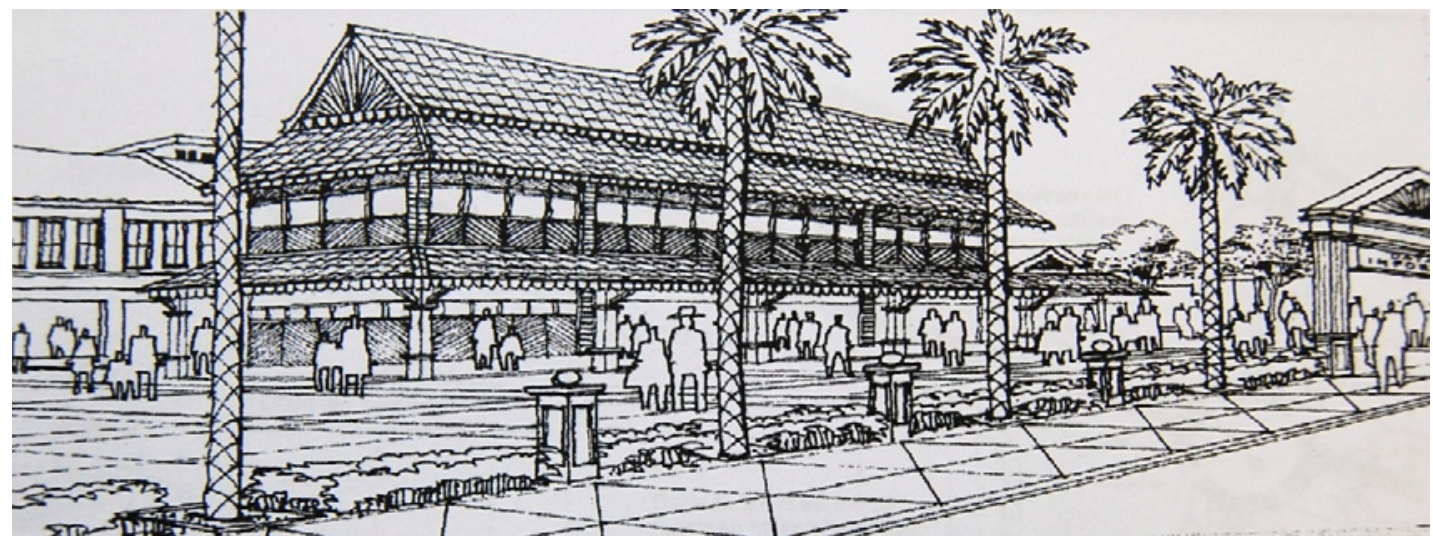

Figure 8. Illustration of design guidance. Here, the building structure is based on the design of Kelantan Malay vernacular architecture style, especially related to the roof style. At the same time, the Islamic design element can be seen through the making of an Arabesque geometry pattern design on the pavement area, planting design and the hard landscape surroundings [12]

\section{Conclusion}

The policy and design guidelines should be reviewed and updated regularly to make sure that the continuity of the vernacular landscape can be preserved. The findings of the study reveal that there is a need for planner, architects, landscape architects, municipal council, designers and local government to have more respect and awareness about conservation of and caring for traditional culture instead of producing more commercial and contemporary designs that do not reflect a sense of place to attract tourist. The Kelantan Malay heritage should be highlighted as a main consideration in the future planning as a new cultural tourism product to avoid further damage or loss of valuable heritage. Meanwhile, a regional vernacular tradition should be set as the focal point in making of the Islamic City of Kota Bharu without mimicking from other Islamic countries and subsequently the concept of the Kota Bharu Islamic City to be promoted as the new cultural tourism product in Malaysia will be successful. 


\section{References}

1. A.Z. Zakaria, I.H. Salleh, M.S.A. Rashid, The Malay garden design concept opportunity to be develop as the tourism product, Hosp. and Tourism: Synergizing creativity and innovation in research 51-68 (2013)

2. ASEAN Tourism marketing strategy 2012-2015, 1, 18 (2012)

3. A.Z. Zakaria, I.H. Salleh, M.S.A. Rashid, In: Procedia - Social and behavioral sciences, 91, 28-35 (2013)

4. http://www.iflaclc.org/definitions.html. UNESCO World heritage cultural landscape definitions in International Federation of Landscape Architects (IFLA), (Accessed 20 June 2014).

5. Sauer, C.O., The morphology of landscape, (1925).

6. Smith, V.L., Hosts and guests: The anthropology of tourism, University of Pennsylvania press, Philadelphia (1979).

7. Petherbridge, G.T. Architectural of the Islamic world: Its history and social meaning, 176-208 (1995)

8. Haider, S.G., The touch of Midas science, values and environment in Islam and the west, 170-208 (1984)

9. MPKB-BI. Kota Bharu landscape master plan report, (2002).

10. http://abunuha.files.wordpress.com/2010/06/img 8712.jpg. (Accessed on June 20,2014).

11. http://abunuha.files.wordpress.com/2010/06/img_8715.jpg. (Accessed on June 20,2014).

12. MPKB-BI. (2006a) Kota Bharu Municipal Council- Islamic city 2006-2015 Master plan report (2002).

13. Selman, P.H., Planning at the landscape scale (2006). 